\title{
Aggression and Violence Directed Toward Physicians
}

\author{
Jeanette L. Morrison, MD, John D. Lantos, MD, Wendy Levinson, MD
}

O ne of the most difficult situations that physicians face is being threatened, abused, or physically harmed by one of their patients. This is not an uncommon problem: Bureau of Labor Statistics (BLS) data for 1995 indicate that more workplace assaults and violent acts occur in health care and social services industries than in any other. ${ }^{1}$ Health care patients, the most common perpetrators of nonfatal workplace violence, were responsible for $45 \%$ of all nonfatal assaults in $1992 .^{2}$ Although the majority of such incidents involve nursing staff, all health care workers are at risk, and physicians are no exception. From 1980 to 1989, 22 physicians were killed while at work. ${ }^{3}$ This represents almost one fourth of all workplacerelated homicides among health care workers during this time period. Physicians may also experience nonfatal violence, ${ }^{4,5}$ verbal abuse or threats, ${ }^{6,7}$ destruction of property, ${ }^{8}$ or intimidation with a weapon..$^{9,10}$

Aggression and violence in the health care setting is costly on a number of levels. Financial losses to the institution as a result of medical expenditures, time away from the job, and psychological counseling have been estimated to be as high as $\$ 107,000$ for a single incident; ${ }^{11}$ workers' compensation claims may add to this amount significantly. ${ }^{12}$ The cost to the individual also extends beyond the immediacy of physical injury. Many of those who are attacked or threatened experience anger, fear, anxiety, self-blame, and loss of confidence. ${ }^{8,13}$ Furthermore, being threatened or harmed while providing care may be difficult to reconcile for a physician who strives to bring compassion and respect to each clinical encounter.

Among doctors, psychiatrists and emergency medicine physicians are believed to be at highest risk of aggression and violence. ${ }^{8}$ This is most likely explained by a combination of clinical and environmental factors. For example, physician inexperience, urban locale, and patient

Received from the Robert Wood Johnson Clinical Scholars Program (JLM), Department of Pediatrics (JDL), and Section of General Internal Medicine, Department of Medicine (WL), University of Chicago, Ill.

Presented in part at the annual meeting of the Society of General Internal Medicine, Washington, DC, May 3, 1997.

Address correspondence and reprint requests to Dr. Morrison: Robert Wood Johnson Clinical Scholars Program, University of Chicago, 5841 S. Maryland MC 2007, Chicago, IL 60637. characteristics such as intoxication, acute psychosis or delirium, and drug-seeking behavior have all been described in the psychiatric and emergency medicine literature as risk factors for aggression and violence. ${ }^{8,14-17} \mathrm{Be}-$ cause these factors also exist in many internal medicine training and practice settings, physical safety is an important and valid concern. However, aggression and violence has not traditionally been a topic discussed by general internists.

The purpose of this article is to provide a general overview of aggression and violence in the health care setting and a more specific focus on violence directed toward physicians by their patients. We hope to make members of the internal medicine community aware of the magnitude and subtleties of violence and to present a framework for understanding and addressing such behavior.

\section{CASE EXAMPLES}

We present three brief cases that demonstrate a variety of clinical examples of aggressive and violent behavior; we will use these cases to discuss some of the situations in which persons may become violent, offer basic strategies for handling dangerous persons, and suggest ways to educate ourselves, prevent harm, and conduct future research.

\section{Case A}

Mr. A is a 50-year-old man with a history of schizophrenia and posttraumatic stress disorder who presented with auditory and visual hallucinations to the acute care clinic at a large, busy, urban hospital. This clinic is staffed entirely by internal medicine residents and does not contain a separate waiting room for psychiatric patients. Mr. A was evaluated by the psychiatry team, and while arrangements for his admission were being processed, he was seated in the main hallway to wait. After waiting for more than 1 hour, Mr. A became agitated and began yelling at the staff in the clinic. When a third-year internal medicine resident approached him, Mr. A picked up a chair and threw it at him, breaking the resident's right hand.

\section{Case B}

Mr. B is a 50-year-old man who was hospitalized on the general medicine service for treatment of cellulitis. On the day he was to be discharged, he became angry and ar- 
gumentative with a nurse when the breakfast that was delivered to him was not what he had ordered. The nurse left the room, and the third-year medical student on the team went to see him in an "attempt to calm him down." His anger escalated, and he threw his water pitcher at the resident. Mr. B's primary physician later commented that he "had a hostile personality" and was often short-tempered with his wife.

\section{Case C}

Mr. C is a 43-year-old man with a past medical history of hypertension and cocaine use. He suffered a massive pontine hemorrhage with resultant Glasgow coma scale score of 3 . Although his family members were told that the prognosis was dismal, they remained optimistic that he would recover completely. At times, they expressed distrust of the medical team. In addition, some members of his family made direct threats and intimidating gestures toward housestaff. For example, the patient's cousin told an internal medicine resident, "If anything happens, you're going to pay," and "I know where to find you."

Five months after his admission, Mr. C suffered cardiopulmonary arrest and could not be resuscitated. The chief resident and one of the interns delivered the news of his death to his family. In response, the patient's mother and a cousin became hostile, accusatory, and verbally abusive. The cousin attempted to punch one of the physicians in the face. Hospital security and city police officers were required to subdue and restrain the family members.

\section{DEFINITIONS}

Researchers and clinicians use a wide range of terminology when reporting and describing "violence." As in other situations, such as child abuse or sexual harassment, what counts as "violence" to one person may be inconsequential or at least acceptable to another. Words such as abuse, threats, assault, battery, combative, and hostile are used interchangeably in the violence literature. ${ }^{5,14,18}$ Thus, it is important to clearly define what we consider to be "violence and aggression." For the purposes of this discussion, we use the definitions of violence and aggression offered by Webster's New World Dictionary:

violence- - . . .physical force used to injure, damage, or destroy. .."

aggression-“. . .a forceful, attacking behavior. . .destructively hostile to others. ..."

Case A clearly fits the description of violence. Indeed, some data sources only collect information on "violence"those acts that result in documentable physical injury such as fractures, lacerations, gunshot wounds, or homicide. ${ }^{3}$ Although these cases may be easier to quantify, ac- tions that either do not result in physical injury (such as case B) or are limited to threats of violence (such as case C) can also be damaging, albeit in somewhat different ways. Verbal and physical aggression of this type can result in significant emotional and financial damage, ${ }^{13}$ and if mismanaged, it may result in physical harm or destruction of property. ${ }^{17}$

\section{MAGNITUDE OF THE PROBLEM}

The Occupational Safety and Health Act of 1970, which mandates that employers provide a workplace "free from recognized hazards that are causing or are likely to cause death or serious physical harm" protects workers from a broad array of hazards such as chemicals, machinery, and communicable disease. ${ }^{19}$ Assaults and violent acts also present a significant, and not uncommon, hazard to employees' health.

Data on the incidence and characteristics of workplace violence are reported annually by the BLS and show consistent patterns between fatal and nonfatal events. Although most violent acts result in minor or temporary injury, aggression and violence account for a significant proportion of all workplace-related deaths. In 1996, for example, $19 \%$ of the 6,100 workplace-related deaths were due to violence, ${ }^{20}$ making this second only to transportation incidents as a cause of fatal occupational injury (and more likely to cause death than falls, contact with objects and equipment, or exposure to harmful substances). To better understand the epidemiology of fatal violence in the health care setting, Goodman and colleagues examined death certificates over a 10-year period (1980-1990). During this time, 522 health care workers died of workrelated injuries, 106 of which were homicides. Twenty-six of those killed were physicians. Though this is certainly an unsettling statistic, the rate of workplace-related homicide for health care workers is far lower than the national average rate for all workers. ${ }^{3}$

Health care workers, however, are among those at highest risk of nonfatal assaults or violence. Of the 22,000 workplace-related cases of violence reported in 1995, 70\% occurred in the health care and social services industries. ${ }^{1}$ Numerous studies have shown that, of all clinical personnel, nursing staff are at the greatest risk of assault. ${ }^{2,21,22}$ The frequent and direct patient contact, predominance of women in the field, and highly accessible work sites have all been offered as explanations for this. ${ }^{23}$ At particularly high risk are those nurses employed in long-term-care facilities, emergency departments, psychiatric wards, or by home health care agencies. ${ }^{22,24} \mathrm{Al}-$ though nursing personnel are at particularly high risk, pharmacists, therapists, and social workers are all known to be vulnerable as well. ${ }^{3,25}$

Assessing the magnitude of violence and aggression directed toward physicians is difficult because there is little definitive information. Accurate data collection is hindered by inconsistencies in the definition and character- 
ization of violence, methodologic limitations, and significant underreporting. Investigators have relied on physician recall, incident reports, or emergency room log books to quantify violent acts. These methods are likely to underestimate the actual rate of violence owing to nonresponse and underreporting.

To investigate the likelihood of underreporting, Brizer and colleagues placed a surveillance videocamera on an inpatient psychiatry ward and counted the number of violent acts over a 2-month period. Fewer than half of the 24 assaults (9 of which were considered "high hostility") were reported. ${ }^{26}$ Clinicians may hesitate to discuss or report violence because they believe it represents an isolated incident of no further consequence or because they believe they provoked the attack. Some may feel ashamed, or think it is "part of the job" to deal with violent patients. ${ }^{27}$

Despite these limitations, numerous investigators have studied violence in two specialized groups of physicians: those who work in the emergency department and psychiatrists. It has been estimated that $40 \%$ of psychiatrists will experience a nonfatal assault at some time during their career. ${ }^{14}$ Many of these events occur in residency training, ${ }^{15,28,29}$ during which violence is actually considered to be "common." 12 The rate of violence toward psychiatrists is highest in emergency departments, prisons, and the forensic units of state hospitals. ${ }^{15}$

Violence is an area of increasing concern for emergency medicine physicians as well. Lavoie and colleagues surveyed 170 emergency department directors about violence; $32 \%$ of the respondents reported at least one verbal threat per day, and $18 \%$ noted that weapons were displayed in a threatening manner at least once per month. ${ }^{10}$ Residents who train in emergency medicine often worry about their safety and the adequacy of security measures at their institution. ${ }^{30}$

In contrast to psychiatry and emergency medicine, there is a paucity of data on violent assaults in the internal medicine literature. In 1994, Paola, Malik, and Qureshi surveyed 100 residents and attending physicians in the Department of Medicine at the Nassau County Medical Center in East Meadow, New York. The authors used legal definitions of "assault" and "battery" to define and categorize violence. Of the 63 respondents, $41 \%$ reported being assaulted and 16\% reported being battered at some time during their career by either a patient or a patient's relative. ${ }^{5}$

\section{RISK FACTORS}

The vast majority of violence in the health care setting is perpetrated by patients. ${ }^{2}$ Sudden, unexpected attacks are rare; most incidents are preceded by mounting tension, frustration, or escalating threats. ${ }^{18,31}$ Anticipating and defusing violence is therefore an important clinical skill for physicians to acquire. Although it is impossible to identify reliably all those who might be dangerous, aggression and violence toward health care workers most commonly involves gang members, narcotic seekers, pris- oners, persons with borderline or antisocial personalities, and patients who are acutely psychotic, manic, or intoxicated. ${ }^{8,17}$ Some consider a history of violence to be the best predictor of future violent behavior. ${ }^{32}$ Other patient factors, including gender, ethnicity, education level, and employment status are not useful in predicting violence. ${ }^{18,32}$

Though less common, acts of aggression and violence can also be initiated by nonpatients. In a 1-year retrospective review of a California emergency department, nonpatients were responsible for nearly one fourth of all violent episodes. ${ }^{9}$ One important group of nonpatients with whom physicians have significant contact is a patient's family members, caretakers, or other acquaintances. Aggression directed toward physicians by this group is exemplified by case $\mathrm{C}$.

Finally, workplace violence has been associated with personal theft, disgruntled former employees, abusive supervisors, and personal or domestic disputes. ${ }^{31,33}$ These actions may occur in all workplaces and are not unique to the health care setting. In addition, workers can be victimized by politically motivated acts of violence or terrorism, such as the bombings at a Massachusetts Planned Parenthood clinic and at the Alfred E. Murrah Federal Building in Oklahoma City. ${ }^{34,35}$

The different ways in which patients regard physicians may explain some of the reasons why aggression and violence occur. For some, violence is a style of communication and conflict resolution; physicians are treated no different from anybody else. Dissatisfaction with one's care, displeasure with the physician's inability to cure, and misdirected anger toward self or family can all be motivating factors for violence. Patients may believe that physicians, like parents, will not abandon them when they behave inappropriately or in socially unacceptable ways. Physicians also represent illness and power; violence may signify attempts to gain some control over unexpected and incomprehensible medical events.

Young physicians and those still in training are most at risk of being assaulted or threatened. ${ }^{8}$ These physicians tend to practice in urban environments and may have more exposure to "high-risk" patients. The relation between gender of the physician and violence is unknown. One might also wonder if racial or ethnic discordance between patient and physician is a predictor of violence. These are interesting questions. Unfortunately, data collected by the BLS do not include information on gender, race, or ethnicity, and to our knowledge, no formal independent studies to investigate these areas have been performed.

The cases we presented above nicely illustrate some of the risk factors and dynamics involved in violent assaults. Recall the case of Mr. A, who was an acutely psychotic patient being cared for by an internal medicine resident in an urban, acute care clinic. When he was left unattended in this loud, busy, unfamiliar environment, his agitation and potential for violence increased and culminated in his throwing a chair at the resident. 
In the second case, Mr. B, who was known by his primary care physician to have "a hostile personality," was dissatisfied with his meal and reacted by throwing a water pitcher. Observed interactions between Mr. B and his wife indicated that this is likely how he dealt with conflict in his own home. It is also possible that there were other aspects of his condition, hospital care, or impending discharge that frightened or frustrated him. Though we in no way condone Mr. B's behavior, this act of aggression may have represented a useful window of opportunity to explore some of these other issues.

Nonpatient violence is demonstrated in the case of $\mathrm{Mr}$. $\mathrm{C}$, whose cousin and mother made repeated threats to his physicians. We do not know if either of them had a history of violent behavior, psychiatric illness, or substance abuse. What is clear, however, is that over the course of Mr. C's hospitalization, they became increasingly frustrated and angry. We suspect that his family members felt guilt (toward themselves) and anger (toward him) for Mr. C's long history of substance abuse that preceded, and most likely contributed to, his fatal stroke. In addition, Mr. C's family did not trust the physicians involved in his care. Although the development of trust is a complex process and the reasons why it failed in this case are not completely known, some of the physicians suspected that race or ethnic discordance between the physicians and the family did play a role. As the family's distrust manifested itself in threats and intimidation, the physicians responded by only engaging in limited, brief conversations. The inability to establish a relationship with the family made it difficult, and ultimately dangerous, to convey necessary information about Mr. C's daily progress, his overall prognosis, and eventually, his death.

\section{A MULTIDISCIPLINARY APPROACH}

Addressing violence and aggression requires an integrated, multidisciplinary approach. A common link among the three cases that we presented is the failure to recognize the systemic causes of frustration and the resulting vulnerability of the physician who seemed responsible, as an individual, to deal with the aggression. Violence prevention and control is a systemic problem that requires the input of administrators, educators, security personnel, and legal staff.

Although hospitals are not required to establish violence prevention programs, recognition of the increasing prevalence of fatal and nonfatal assaults in the health care setting prompted the Occupational Safety and Health Administration (OSHA) to publish guidelines that specifically focus on the problem of violence inflicted by patients against staff. ${ }^{19}$ Published in 1996, these guidelines outline the essential elements of a violence prevention program in the health care setting and provide sample incident reporting forms and surveillance surveys. Although it is beyond the scope of this article to review all of these strategies in detail, we highlight the key components to a successful violence prevention program and provide physician-specific discussion of each:

1. A commitment from health care administrators and physician educators to acknowledge the reality of violence and to allocate resources for the development of training, crisis management, debriefing, and surveillance programs.

Administrative support not only legitimizes violence toward physicians as an important problem, but also provides the impetus for systemwide involvement. Many institutions have established detailed intervention procedures for handling dangerous situations; ${ }^{36}$ at a minimum, security officers should be actively involved whenever personal safety is felt to be at risk. After a violent incident, a debriefing session is recommended. This provides the opportunity for injury assessment and supportive counseling. ${ }^{36}$ To evaluate the success of a program and ensure accurate surveillance of ongoing violence, prompt reporting of all threats and assaults is necessary and is the responsibility of the individual involved.

Legal counseling is an important part of the debriefing process for both the individual and the hospital. Health care employees who are injured by violence during the course of their work are usually eligible for workers' compensation, but generally cannot sue their employer for negligence. ${ }^{37}$ Although the General Duty Clause of the Occupational Safety and Health Act does require employers to provide a workplace "free from recognizable hazards," whether or not a legally defined duty exists to warn health care workers of patients known to be dangerous is not firmly established. Administrators can, however, be cited by OSHA for failing to prevent or abate a recognized hazard of workplace violence. ${ }^{19}$

2. The development of training and educational programs for employees, supervisors, managers, and security personnel.

Educational programs for physicians should include the practical skills necessary for recognizing and responding to violence. It is important to be able to differentiate between angry, frustrated, or "difficult" patients and those who may actually cause physical or emotional harm. This requires observation for specific behavioral cues and discussion between doctor and patient. For example, a person who is sitting tensely on the edge of his seat, using loud, pressured, or threatening speech, or who is agitated and pacing should be viewed as potentially violent by the physician. ${ }^{17}$ When working with potentially violent individuals, physicians should be direct, nonargumentative, and honest. Experts recommend asking straightforward questions, such as "Do you plan to harm me?", and clearly conveying that violence is unacceptable. ${ }^{17}$

Behavioral cues were present in all three of the cases presented. Mr. A was increasingly agitated and began yelling prior to throwing a chair, Mr. B was argumentative and angry with the nursing staff prior to throwing a pitcher, and Mr. C's family had been making direct 
threats and intimidating gestures for 5 months. Unfortunately, only in case B was this behavior recognized and addressed appropriately. In this case, after Mr. B threw the pitcher, the medical student left the room and returned with her senior resident. The resident calmly told Mr. B that no further acts of aggression or destruction would be tolerated.

Physicians also need to trust their "gut instincts" and feelings. A useful rule of thumb is to heighten one's suspicion when dealing with any individual who makes one uneasy and to take action when one feels threatened or frightened. ${ }^{18}$ As internists, we are trained to collect and analyze data. A displaced PMI, a rising creatinine level, and a blood pressure of $80 / 40$ are all data with familiar meanings that we know how to interpret because we have been trained to do so; we should recognize that our feelings and instincts are reliable data as well.

In a dangerous situation, there are numerous personal precautions that physicians can take to ensure their safety. Simple to implement, these strategies include maintaining physical distance, never turning one's back on a potentially violent person, always staying between the door and the potentially violent person, to be certain of a safe exit, and removing dangling items that can be used as weapons, such as stethoscopes, neckties, or jewelry. ${ }^{17,18}$

Incorporating these clinical skills into medical school, residency, and continuing medical education classes is an essential step in the prevention and management of violence. Recognizing that societal violence is an important public health topic, physicians are being encouraged to include interpersonal violence assessment and intervention in their training and practices. ${ }^{38,39}$ Addressing violence directed toward physicians in this developing curriculum will help to broaden the focus of these discussions and provide useful information to students regardless of the specialty they choose. Case presentations, discussion groups, and didactic sessions with practical advice are all potential forums for education. There are publications that can assist as well, including the American Psychiatric Association's Guide to Clinician Safety, ${ }^{14}$ a booklet from the Young Physician's Section of the American Medical Association, entitled "Violence in the Medical Workplace," 8 and a recently published syllabus by Lion and Scaletta. ${ }^{40}$

Educational programs for physicians also need to acknowledge and support the effect that aggression and violence can have on an individual. Examining the aftermath of the case of $\mathrm{Mr}$. C demonstrates the range of emotions that can result. Subsequent to Mr. C's death, an organized discussion was held with the housestaff and attending physicians who had cared for him during his prolonged hospitalization. There, more than 30 interns and residents recalled their experiences with this patient. Almost all were fearful of and felt intimidated by his family. Many residents felt abandoned, stating that the attending physicians were not supportive of their concerns, a problem attributed to lack of experience with such situations. Although many residents were uncomfortable interacting with this particular family, they felt that it was part of their job as physicians to deal with "difficult" individuals, be they patients or, in this case, family. Some expressed feelings of guilt, blaming themselves for not developing a stronger relationship with the family. Others had denied to themselves the possibility that physical violence could actually result. In addition, because the family had mentioned bringing legal suit against the hospital, residents felt that every effort should be made to accommodate their anger. The feelings of guilt, denial, fear (of litigation), and inadequacy generated by this case are common responses to aggression and violence. ${ }^{13}$ As in this case, these emotions can be important barriers to open, constructive discussion. Educational efforts should acknowledge these barriers and provide a supportive environment in which to understand and process them.

3. Ongoing work site analysis to identify existing or potential hazards for violence and the implementation of measures to prevent or control such hazards.

Ensuring a safe practice environment in the health care setting is another component to a violence prevention program. Because long delays have been associated with frustration and violence, the waiting area should include diversions such as patient education materials, magazines, open space, and available telephones. ${ }^{8,9}$ Further measures such as panic buttons, flags on charts of high-risk patients, and metal detectors may be implemented in specific high-risk settings. ${ }^{8,36}$ There is evidence that such measures are effective and do not detract from patient care. ${ }^{41}$ It is not known, however, if these strategies are appropriate for internal medicine training and practice settings.

Of the three cases we presented, case A, that of the acutely psychotic patient in the acute care clinic, provides the most obvious example of a violence-prone work site: Mr. A was placed in an inappropriate environment, and cared for by internal medicine residents with little training or experience in the management of psychotic patients. Emergency departments or acute care clinics that serve a large population of psychiatric patients should be equipped, both in terms of personnel and space, to handle potentially aggressive or violent patients.

\section{SUMMARY}

Physicians harmed by the people for whom they provide care experience a unique type of workplace violence. Because general internists have responsibilities in a wide range of clinical settings, the potential for aggression and violence is a realistic concern. The significant emotional, psychological, and financial costs of violence make this an important issue for us all. It is crucial for general internists to recognize the various forms of violent behavior, to address the clinical and institutional factors that both perpetuate and result from patient violence, and to be aware of the appropriate security measures to take in a 
dangerous situation. Guidelines published by OSHA, ${ }^{19}$ the Joint Commission on Accreditation of Health Care Organizations, ${ }^{42}$ and a number of professional organizations such as the American Medical Association ${ }^{8}$ and American Psychiatric Association ${ }^{14}$ are valuable resources for practicing clinicians and educators.

The three cases we have presented exemplify how aggression and violence can manifest in the internal medicine setting. Within internal medicine, it is likely that certain clinicians are at increased risk, such as those who care for patients in the emergency department, on psychiatric wards, in substance abuse programs, and in prisons. Regardless of where one trains or practices, however, the possibility of encountering an aggressive or violent individual will always exist. The belief that physicians are exempt from physical violence because of their status, power, prestige, or knowledge is a myth.

Efforts to address this problem should be aimed at better understanding the situations in which violence occurs and the unique way in which violence affects general internists. Future research is needed to describe the epidemiology of aggression and violence toward physicians and to evaluate the efficacy of educational programs and interventions designed to prevent its occurrence.

\section{REFERENCES}

1. Bureau of Labor Statistics. Nonfatal Occupational Injuries Due to Assault and Violent Acts. Washington, DC: U.S. Department of Labor; 1995.

2. Toscano G, Weber W. Violence in the Workplace. Washington, DC: Bureau of Labor Statistics; 1995

3. Goodman RA, Jenkins L, Mercy JA. Workplace-related homicide among health care workers in the United States, 1980 through 1990. JAMA. 1994;272:1686-8.

4. Neville RG. Violent patients in general practice. The Practitioner. 1986;230:1105-8.

5. Paola F, Malik T, Qureshi A. Violence against physicians. J Gen Intern Med. 1994;9:503-6.

6. D'Urso P, Hobbs R. Aggression and the general practitioner. BMJ. 1989;298:97-8.

7. O'Connell P, Bury G. Assaults against general practitioners in Ireland. Fam Med. 1997;29:340-3.

8. American Medical Association Young Physicians Section. Violence in the Medical Workplace: Prevention Strategies. Chicago, Ill: AMA; 1995

9. Pane GA, Winiarski AM, Salness KA. Aggression directed toward emergency department staff at a university teaching hospital. Ann Emerg Med. 1991;20:283-6.

10. Lavoie FW, Carter GL, Danzi DF, Berg RL. Emergency department violence in United States teaching hospitals. Ann Emerg Med. 1988;17:143-9.

11. Hunter M, Carmel $\mathrm{H}$. The cost of staff injuries from inpatient violence. Hosp Community Psychiatry. 1992;43:586-8.

12. Black KJ, Compton WM, Wetzel M, Minshin S, Farber NB, Rastogi-Cruz D. Assaults by patients on psychiatric residents at three training sites. Hosp Community Psychiatry. 1994;45:706-10.

13. Lanza ML. The multiple costs of patient assault. In: Dubin WR, Futrell DE, Lion JR, eds. Creating a Secure Workplace: Effective Policies and Practices in Health Care. Chicago, Ill: American Hospital Publishing Inc.; 1996:25-39.

14. American Psychiatric Association. Task Force Report on Clinician Safety. Washington, DC: American Psychiatric Press; 1992.
15. Madden DJ, Lion JR, Penna MW. Assaults on psychiatrists by patients. Am J Psychiatry. 1976;133:422-5.

16. Foust D, Rhee KJ. The incidence of battery in an urban emergency department. Ann Emerg Med. 1993;22:583-5.

17. Dubin WR. Evaluating and managing the violent patient. Ann Emerg Med. 1981;10:481-4.

18. Rice MM, Moore GP. Management of the violent patient: therapeutic and legal considerations. Emerg Med Clin North Am. 1991;9:13-30.

19. Occupational Safety and Health Administration. Guidelines for Preventing Workplace Violence for Health Care and Social Service Workers. Washington, DC: U.S. Department of Labor; 1996.

20. Bureau of Labor Statistics. Fatal Occupational Injuries by Occupation and Event or Exposure. Washington, DC: U.S. Department of Labor; 1996.

21. Yassi A. Assault and abuse of health care workers in a large teaching hospital. Can Med Assoc J. 1994;151:1273-9.

22. Williams MF. Violence and sexual harassment. AAOHN J. 1996: 44:73-7.

23. Dubin WR, Lion JR. Violence against the medical profession. In: Dubin WR, Futrell DE, Lion JR, eds. Creating a Secure Workplace: Effective Policies and Practices in Health Care. Chicago, Ill: American Hospital Publishing Inc.; 1996:3-14.

24. Hunter E. Violence prevention in the home health setting. Home Healthcare Nurse. 1997;15:403-9.

25. Bernstein H. Survey of threats and assaults directed toward psychotherapists. Am J Psychother. 1981;35:542-9.

26. Brizer DA, Crowner ML, Convit A, Volavka J. Videotape recording of inpatient assaults: a pilot study. Am J Psychiatry. 1988;145:751-2.

27. Harris A. Violence in general practice. BMJ. 1989;298:63-4.

28. Whitman RM, Armao BB, Dent OB. Assault on the therapist. Am J Psychiatry. 1976;133:426-9.

29. Fink D, Shroyer B, Dubin W. A study of assaults against psychiatric residents. Acad Psychiatry. 1991;15:94-9.

30. Anglin D, Kyriacou DN, Hutson HR. Residents' perspectives on violence and personal safety in the emergency department. Ann Emerg Med. 1994;23:1082-4.

31. Feldman TB, Holt J, Hellard S. Violence in medical facilities: a review of 40 incidents. Ky Med Assoc J. 1997;95:183-9.

32. Goldberg SB, Lion JR. Violence in the emergency department. In: Dubin WR, Futrell DE, Lion JR, eds. Creating a Secure Workplace: Effective Policies and Practices in Health Care. Chicago, Ill: American Hospital Publishing Inc.; 1996:265-76.

33. Bachman R. Epidemiology of violence and theft in the workplace. Occup Med. 1996;11:237-41.

34. Gates DM. Workplace violence. AAOHN J. 1995;43:536-44.

35. Simonowitz JA. Health care workers and workplace violence. Occup Med. 1996;11:277-91.

36. Ordog GJ, Wasserberger J, Ordog C, Ackroyd G, Atluri S. Violence and general security in the emergency department. Acad Emerg Med. 1993;2:151-4.

37. Belden LR, Moniz DM. The hospital's liability for safety. In: Dubin WR, Futrell DE, Lion JR, eds. Creating a Secure Workplace: Effective Policies and Practices in Health Care. Chicago, Ill: American Hospital Publishing Inc.; 1996:153-76.

38. Conway T. The internist's role in addressing violence. Arch Intern Med. 1996;156:951-6.

39. Alpert EJ, Seger RD, Bradshaw YS. Interpersonal violence and the education of physicians. Acad Med. 1997;72:S41-50.

40. Lion JR, Scaletta T. Appendix. Teaching violence prevention to health care workers. In: Dubin WR, Futrell DE, Lion JR, eds. Creating a Secure Workplace: Effective Policies and Practices in Health Care. Chicago, Ill: American Hospital Publishing Inc.; 1996:309-11.

41. McNamara R, Yu DK, Kelly JJ. Public perception of safety and metal detectors in an urban emergency department. Am J Emerg Med. 1997;15:40-2.

42. Joint Commission on Accreditation of Healthcare Organizations. Accreditation Manual for Hospitals. Oakbrook, Ill.: JCAHO;1994. 